\title{
Trichothecene Genotype Composition of Fusarium graminearum Not Differentiated Among Isolates from Maize Stubble, Maize Ears, Wheat Spikes, and the Atmosphere in New York
}

\author{
Paulo R. Kuhnem, Pierri Spolti, Emerson M. Del Ponte, Jaime A. Cummings, and Gary C. Bergstrom
}

First, second, fourth, and fifth authors: School of Integrative Plant Science, Section of Plant Pathology and Plant-Microbe Biology, Cornell University, Ithaca, NY 14853-5904; and first, second, and third authors: Departamento de Fitossanidade, Universidade Federal do Rio Grande do Sul, Porto Alegre, RS 91540000, Brazil.

Current address of E. M. Del Ponte: Departamento de Fitopatologia, Universidade Federal de Viçosa, Viçosa, MG, 36570-900, Brazil.

Accepted for publication 12 January 2015.

\begin{abstract}
Kuhnem, P. R., Spolti, P., Del Ponte, E. M., Cummings, J. A., and Bergstrom, G. C. 2015. Trichothecene genotype composition of Fusarium graminearum not differentiated among isolates from maize stubble, maize ears, wheat spikes, and the atmosphere in New York. Phytopathology 105:695-699.

In order to test the hypothesis that the trichothecene genotype composition of local populations of Fusarium graminearum is structured by specific habitats, a collection of 1,407 isolates was obtained from overwintered maize stubble, mature maize ears and wheat spikes, and the atmosphere $1.5 \mathrm{~m}$ aboveground during the flowering stage of these crops. These isolates were sampled at three diverse agricultural locations in New York State: namely, Aurora (sampled in 2012 and 2013) in central New York, Belmont (sampled in 2013) in southwestern New York, and Willsboro (sampled in 2013) in northeastern New York. Approximately 100 isolates of $F$. graminearum from each habitat were collected within a $10-$ mile $^{2}$ area in each location. Polymerase chain reaction assays were

used to identify three main B-trichothecene genotypes-3-acetyldeoxynivalenol (3-ADON), 15-ADON, or nivalenol (NIV) - based on amplification of portions of Tri3 and Tri12 genes. All but the NIV genotype were detected. The 15-ADON genotype predominated in most locations; frequencies were 92\% (652/709) at Aurora, 78\% (332/379) at Belmont, and 53\% (167/319) at Willsboro. Frequencies of any genotype did not differ in general among the four habits in each location. An exception was in Aurora 2012, where only 5 in 243 -ADON isolates were found in samplings from the air and grains of both crops. As viewed by the composition of trichothecene genotypes, local populations of $F$. graminearum appear not to be structured by these four habitats inclusive of pathogenic and saprophytic phases of the fungus life cycle. The similar frequency of 3-ADON and 15-ADON in eastern New York (Willsboro), which is less than $400 \mathrm{~km}$ away from the Aurora sampling location in the central area of the state, suggests that regional populations may be differentiated based on selection associated with climatic or landscape features not currently identified.
\end{abstract}

In North America, Fusarium graminearum is the main trichothecene-producing member of the $F$. graminearum species complex (FGSC) associated with Fusarium head blight (FHB) and Gibberella ear rot (GER) epidemics in wheat and maize, respectively $(26,28)$. F. graminearum occurs in three main strain-specific profiles of B-trichothecene mycotoxin production: (i) nivalenol (NIV) and its acetyl-derivatives (ii) deoxynivalenol (DON) and primarily 3acetyldeoxynivalenol (3-ADON) and (iii) DON and primarily 15ADON chemical phenotypes (chemotypes) (27). To overcome the challenge of chemical analysis for chemotype determination in large sample sizes, cost-effective molecular assays were developed and have been used to identify and monitor the geographical distribution of trichothecene genotype as predictive of the chemotype of individual isolates $(12,15,34,37,41,46)$. The main FHB pathogen in North America, F. graminearum, most commonly possesses the 15 -ADON genotype or chemotype $(41,47)$ but the 3 -ADON and NIV genotypes have also been reported $(11,12,39,41)$. Increasing frequencies of 3-ADON isolates from the southeastern (North Carolina) to the northeastern (New York) United States have been documented (41). Similarly, the frequency of the 3-ADON isolates was found to increase in north-central areas in the United States and in western Canada $(23,47)$. NIV isolates have been absent or appeared in very low frequencies in most surveys conducted in North America

Corresponding author: G. C. Bergstrom; E-mail address: gcb3@cornell.edu

http://dx.doi.org/10.1094/PHYTO-10-14-0266-R

(c) 2015 The American Phytopathological Society
$(5,41,43)$. Nevertheless, NIV genotypes were found among isolates from small wheat-producing regions of Louisiana that were close to rice-growing regions, in a high proportion $(79 \%)$ of the population (11). Ward et al. (46) suggested that trichothecene genotype diversity has been maintained by selection, indicating that genotype differences can have important consequences for the fitness of the reproducing organism. In fact, several studies have reported differences related to aggressiveness, toxin accumulation, growth rate, and production of conidia between the two trichothecene genotypes (3-ADON and 15$\mathrm{ADON}$ ) of $F$. graminearum occurring in North American wheat $(13,33,45,47)$. However, a recent study with relatively large sampling (42) reported no differences in either saprophytic or pathogenic fitness measures among $F$. graminearum isolates possessing 3- or 15-ADON trichothecene genotypes from New York.

Studies in South Africa (4) and Brazil (6) have shown a drastic difference in the frequency of phylogenetic species of the complex collected from maize stubble compared with wheat kernels, where species with the NIV genotype were more frequently isolated from maize and the 15-ADON or 3-ADON genotypes from wheat. Thus, the difference in genotype frequency could be associated with ecological specialization at the species level (4) rather than an adaptive advantage of the trichothecene genotype.

Conservation tillage has increased in recent decades in North America, and overwintered crop residues such as maize stubble are the primary source of inoculum for both FHB and GER epidemics $(9,31,32)$. Maintenance of these crop residues might affect the dynamics and composition of $F$. graminearum populations (9), as well as influence the spread of $F$. graminearum spores (18). Variations in landscape may affect how genotypes are dispersed in 
space, and more homogeneous landscapes (greater areas and proximities of susceptible crops) may facilitate the spread of pathogenic genotypes more efficiently than more heterogeneous landscapes (25). Population genetic studies have shown a substantial genetic divergence between $F$. graminearum populations spread across large areas of North America $(11,12,23,47)$, and some genetic isolation may occur on a regional scale (40).

Pathogenic populations causing FHB in wheat are much better characterized than those causing GER in maize in regard to species/ trichothecene genotype composition $(28,29,35,36)$. In New York, both the 3-ADON and 15-ADON genotypes have been found in F. graminearum isolates obtained from wheat (38) (G. C. Bergstrom, unpublished) and a limited sampling of maize ears (G. C. Bergstrom, unpublished). Differences in aggressiveness $(10,13)$, geographical distribution $(15,41)$, host, and habitat preference $(4,6)$ within members of the FGSC raise questions about their adaptation to different hosts or environments, and such traits may or may not be linked to trichothecene genotypes.

The main objective of this study was to assess whether the trichothecene genotypes in a large regional collection of $F$. graminearum isolates are structured by habitats spanning two hosts and the saprophytic and the pathogenic phases of the fungus. To address this objective, over a thousand isolates were obtained from four habitats, including maize stubble, maize ears, wheat spikes, and the atmosphere above the crop canopy, in three diverse agricultural locations in New York State.

\section{MATERIALS AND METHODS}

Study areas and sampling scheme. Based on previous surveys (G. C. Bergstrom, unpublished), we knew that 15-ADON isolates predominated on symptomatic wheat spikes in the major maize and wheat production areas of central and western New York, whereas there was a much higher frequency of 3-ADON isolates on wheat in areas of eastern New York. Therefore, isolates were collected in three distinct locations representing diverse agricultural regions of New York State during the 2012 and 2013 growing seasons. These three locations were (i) Aurora, sampled in 2012 and 2013, Cayuga County, central New York, Central Plain Region, mostly level with widespread grain crops production; (ii) Belmont, sampled in 2013, Allegany County, southwestern New York, Allegany Plateau Region, a hilly, forested region with crops grown in narrow valleys; and (iii) Willsboro, sampled in 2013, Essex County, northeastern New York, Champlain Valley Region, a broad valley with scattered farms between the Adirondack Mountains and Lake Champlain (Fig. 1). In each of the four location-years, samplings were made from four fungal habitats that represented stages of the fungus life cycle and spanned the saprophytic and pathogenic phases: overwintered maize stubble, symptomatic maize ears, symptomatic wheat spikes, and air.

Collection and isolation procedures. To compose the saprophytic collections, in each visited field, 150 maize stubble segments exhibiting perithecia were collected. In the laboratory, the stalks were immersed in $0.2 \%$ sodium hypochlorite for $30 \mathrm{~s}$, rinsed three times in sterile deionized water, placed on sterile paper towels, allowed to dry in a laminar flow hood, and stored at $4^{\circ} \mathrm{C}$ until processed. Before processing, the stubble pieces were surface disinfested by being immersed in $70 \%$ ethanol for $30 \mathrm{~s}, 0.2 \%$ sodium hypochlorite for $30 \mathrm{~s}$, and rinsed three times in sterile deionized water. Under a microscope, one perithecium per stalk was placed on a potato dextrose agar (PDA) plate containing streptomycin at $40 \mathrm{mg}$ liter $^{-1}$. Isolations were made from the perithecial colonies, which were purified through a single-spore technique (22).

To compose the airborne collections, fungal isolates were collected on petri plates containing Nash-Snyder medium (22) mounted on stationary spore traps positioned aboveground $(1.5 \mathrm{~m})$ in each of the three locations. Samplings were made during 10 days around the flowering period. After a day of exposure to the environment (9:00 A.M. to 9:00 A.M.), six plates filled with a medium that was highly inhibitory to bacteria and fungi other than Fusarium spp. were covered with a lid and returned to the laboratory, where they were incubated for 4 to 5 days at room temperature $\left(22^{\circ} \mathrm{C}\right)$ under ambient light conditions (40). From each of these plates, four $F$. graminearum candidate colonies were isolated on PDA and single spored (22).

To compose the collections from diseased wheat spikes and maize ears, symptomatic mature kernels from both crops were

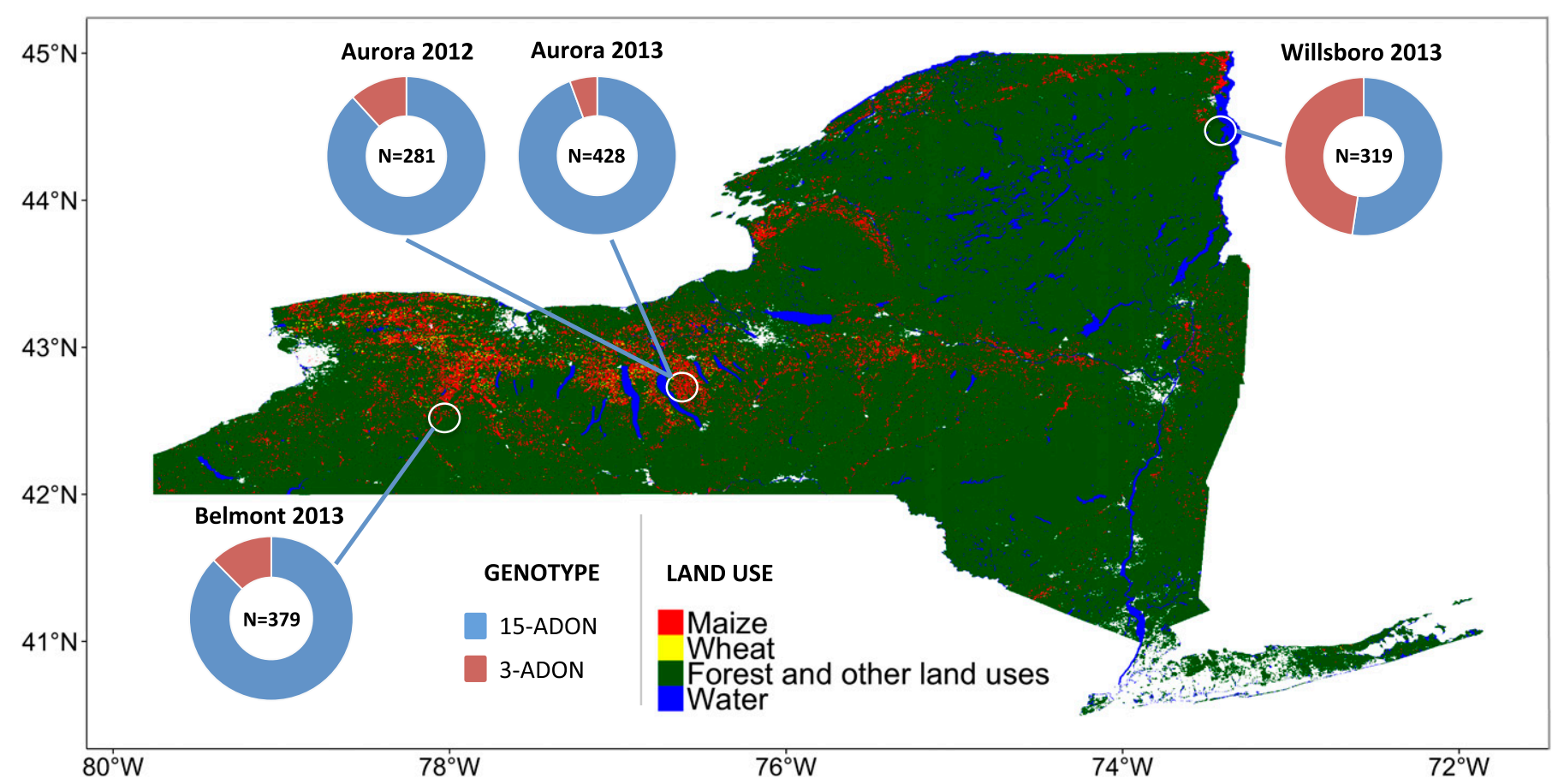

Fig. 1. New York land use map and relative frequencies of two trichothecene genotypes (3-acetyldeoxynivalenol and 15-acetyldeoxynvalenol) of Fusarium graminearum in New York in 2013. Map Source: CropScape-Cropland data layer (NASS/USDA). 
surface disinfested (5 min in $70 \%$ ethanol, 5 min in $0.5 \% \mathrm{NaOCl}$, and rinsed twice for $2 \mathrm{~min}$ in sterile distilled water), dried in a laminar flow hood, placed on PDA media containing streptomycin at $40 \mathrm{mg}$ liter ${ }^{-1}$, and incubated for 6 days at room temperature $\left(22^{\circ} \mathrm{C}\right)$ under ambient light conditions. No more than one kernel per wheat spike or maize ear was selected. Fusarium colonies were subcultured on PDA plates using a single-spore technique (22). All purified isolates were labeled and subsequently stored in $15 \%$ glycerol at $-80^{\circ} \mathrm{C}$ at the Section of Plant Pathology and Plant Microbe-Biology, Cornell University, Ithaca, NY.

DNA extraction and polymerase chain reaction assay. Fungal mycelia were collected from 7-day-old $F$. graminearum cultures growing on PDA medium. DNA was extracted using PrepMan Ultra Sample Preparation Reagent (Life Technologies, CA) protocol. After extraction, a nucleic acid precipitation method was used to reduce potential polymerase chain reaction (PCR) inhibitors in each sample. Samples were stored at $-20^{\circ} \mathrm{C}$ until the thermal cycling protocol. PCR assays (GoTaq Green Master Mix; Promega Corp., Madison, WI) were used to identify B-trichothecene genotypes 3-ADON, 15-ADON, or NIV based on amplification of portions of Tri3 and Tri12 genes $(43,47)$. Resulting PCR products were separated by agarose gel electrophoresis and visualized under UV illumination.

Data analysis. The $\chi^{2}$ test was used to determine whether the observed frequencies (counts) in the different genotypes and habitats (two-by-four contingency table) markedly differed from the frequencies that we would expect by chance for each of the four location-years. The $\chi^{2}$ test was performed using PROC FREQ in SAS (version 9.2, Statistical Analysis System; SAS Institute, Cary, NC).

\section{RESULTS}

In total, 1,407 isolates were obtained and genotyped statewide. The number of isolates ranged from 281 to 428 isolates among the locations and from 16 to 150 among habitats within a location (Fig. 1; Table 1). The molecular assay based on Tri3 and Tri12 gene portions showed that the 15 -ADON genotype was dominant overall $(82 \%, 1,151 / 1,407)$, followed by the 3 -ADON genotype $(18 \%, 256 / 1,407)$. The NIV genotype was not detected. With the exception of the Willsboro location, where 3-ADON and 15ADON were found in similar proportion $(48 \%, 152 / 319$ and $52 \%$, $167 / 319$, respectively), $15-$ ADON was the predominant $(90 \%$, 984/1,088) genotype in the other three location-years (Fig. 1; Table 1).

The $\chi^{2}$ test revealed that the frequency of the trichothecene genotypes did not differ significantly between years (2012 and $2013)$ in the Aurora location $\left(\chi^{2}=1.526, P=0.217\right)$. In 2012, overall frequency was $88 \%(248 / 281)$ of the 15 -ADON genotype and $12 \%(33 / 281)$ of the 3-ADON genotype whereas, in 2013, 15 ADON and 3-ADON genotypes represented 94\% (404/428) and $6 \%(24 / 428)$ of the population, respectively (Table 1$)$.

When frequencies of the two genotypes were compared among the four habitats within each location-year, significant difference was found only in Aurora in 2012 (Table 1). In Aurora 2013, 15 -ADON genotype frequency was $>94 \%$ in all four habitats $\left(\chi^{2}=0.192, P=0.979\right)$. A similar trend was observed in Belmont $\left(\chi^{2}=8.137, P=0.053\right)$, where $>80 \%$ of the isolates were of the 15 ADON genotype (Table 1). Even in Willsboro, where frequency of 3 -ADON and 15-ADON were similar, no difference was found among the four habitats $\left(\chi^{2}=7.593, P=0.055\right)$, with 3 -ADON and $15-\mathrm{ADON}$ at 46 and $54 \%, 38$ and $62 \%, 44$ and $56 \%$, and 57 and $43 \%$ on maize stubble, maize ears, wheat spikes, and the atmosphere, respectively (Table 1). In Aurora 2012, the 3-ADON genotype was not found $(0 / 26)$ in symptomatic wheat spikes and it was relatively higher in maize stubble $(20 \%, 18 / 89)$, thus leading to differences in the frequency of the two genotypes among the habitats $\left(\chi^{2}=26.395\right.$, $P<0.001)$ (Table 1).

\section{DISCUSSION}

This was the first comprehensive study conducted in North America to investigate and compare frequencies of the main trichothecene genotypes among $F$. graminearum isolates obtained from the saprophytic, airborne, and pathogenic stages of the fungus life cycle, especially from the two maize habitats. Although we could not accurately determine species composition based on our data, it is likely that these are part of a North American population of $F$. graminearum in which the diversity of trichothecene genotypes is highly structured in relation to genetic populations that are highly divergent $(12,14,16,23,33,40,41)$. As viewed by the composition of the only two main trichothecene genotypes found in the region, with the 15-ADON genotypes largely dominating in most locations, populations of $F$. graminearum in three diverse locations in New York appeared not to be structured by the four habitats analyzed, which showed similar frequencies of the same trichothecene genotype. An exception was a somewhat higher frequency of the 3 -ADON genotype in maize stubble and no 3-ADON found in wheat spikes in Aurora in 2012, which may be related to less favorable weather conditions for the disease in that season, thus leading to a relatively small sample size from pathogenic stages.

Our results contrast with surveys in other countries, where differences in trichothecene genotype composition from these habitats were related to differences in species composition of FGSC, which was shown to be structured by trichothecene genotypes $(4,6)$. In southern Brazil, Del Ponte et al. (6) found that, although $F$. meridionale and F. cortaderiae, both of the NIV genotype, were the most frequent species found in maize stubble on wheat fields, pathogenic collections from symptomatic wheat kernels in these fields were largely dominated by $F$. graminearum of the 15-ADON genotype. Interestingly, it has been suggested that FHB risk was higher when wheat followed maize than when wheat followed soybean (9), which may apply to the surveyed and other regions in the United States where there is an apparent continuum (3) in population structure of $F$. graminearum from maize stubble, the primary inoculum source for both FHB and GER epidemics $(20,31,32,44)$.

The locations surveyed in New York differed in climatic pattern and cropping systems. Aurora and Belmont are in relatively warmer

TABLE 1. Trichothecene genotype frequency of Fusarium graminearum isolates collected from maize stubble, air, and wheat and maize kernels in three agricultural locations in New York

\begin{tabular}{|c|c|c|c|c|}
\hline \multirow[b]{2}{*}{ Locality-year } & \multirow[b]{2}{*}{ Habitat } & \multicolumn{2}{|c|}{ Number of isolates $(\%)^{\mathrm{a}}$} & \multirow[b]{2}{*}{$N^{\mathrm{b}}$} \\
\hline & & 3-ADON & 15-ADON & \\
\hline \multirow[t]{5}{*}{ Aurora-2012 } & Maize stubble & $18(20.2)$ & $71(79.8)$ & 89 \\
\hline & Air & $4(9.3)$ & $136(90.7)$ & 150 \\
\hline & Wheat spike & $0(0.0)$ & $26(100.0)$ & 26 \\
\hline & Maize ear & $1(6.2)$ & $15(93.8)$ & 16 \\
\hline & Subtotal & 33 (11.7) & $248(88.3)$ & 281 \\
\hline \multirow[t]{5}{*}{ Aurora-2013 } & Maize stubble & $5(5.3)$ & $89(94.7)$ & 94 \\
\hline & Air & $9(5.9)$ & $144(94.1)$ & 153 \\
\hline & Wheat spike & $5(5.0)$ & $95(95.0)$ & 100 \\
\hline & Maize ear & $5(6.2)$ & $76(93.8)$ & 81 \\
\hline & Subtotal & $24(5.6)$ & $404(94.4)$ & 428 \\
\hline \multirow[t]{5}{*}{ Belmont-2013 } & Maize stubble & $19(20.0)$ & $76(80.0)$ & 95 \\
\hline & Air & $9(8.1)$ & $102(91.9)$ & 111 \\
\hline & Wheat spike & $12(12.8)$ & $82(87.2)$ & 94 \\
\hline & Maize ear & $7(8.9)$ & 72 (91.9) & 79 \\
\hline & Subtotal & $47(12.4)$ & $332(87.6)$ & 379 \\
\hline \multirow[t]{6}{*}{ Willsboro-2013 } & Maize stubble & $30(46.2)$ & $35(53.8)$ & 65 \\
\hline & Air & $58(57.4)$ & $43(42.6)$ & 101 \\
\hline & Wheat spike & $43(43.9)$ & $55(56.1)$ & 98 \\
\hline & Maize ear & $21(38.1)$ & $34(61.8)$ & 55 \\
\hline & Subtotal & $152(47.6)$ & $167(52.4)$ & 319 \\
\hline & Total & $256(18.2)$ & $1151(81.8)$ & 1407 \\
\hline
\end{tabular}

a Genotypes 3-acetyldeoxynivalenol (3-ADON) and 15-acetyldeoxynvalenol (15-ADON).

b $\mathrm{N}=$ total number of isolates. 
regions, with large acreage of maize and wheat grown in rotation with other crops. Willsboro is located in a colder, broad valley with scattered farms between the Adirondack Mountains and Lake Champlain, with some maize and very little small grains production. Such differences in landscape among these locations may have influenced the composition of the trichothecene genotypes. Previous studies have reported both a cline in prevalence of the 3ADON genotype in wheat grains from west to east in Canada (47) and a cline of increasing frequency of 3-ADON genotype from North Carolina (south) to New York (north) in the United States (41). Indeed, the predominance of 15-ADON isolates in wheat and maize in Aurora and Belmont is consistent with previous collections of isolates in winter wheat in western New York in 2007 (41) and during 2011 to 2014 (G. C. Bergstrom, unpublished). The equal proportions of 3-ADON and 15-ADON isolates in wheat kernels in Willsboro was also not surprising because frequencies of 3-ADON exceeding 30\% have been observed in other areas of eastern New York and in Vermont (G. C. Bergstrom, unpublished).

Climatic factors have been reported associated with 3-ADON and 15-ADON frequencies of FGSC in wheat and maize. In China, 3ADON isolates were found at a higher frequency in the warmer, wheat-growing areas of the Yangtze River valley, while 15-ADON isolates dominated in colder regions in southern China $(17,30)$; this is an association with temperature opposite to that observed in New York. In southern Brazil, FGSC members possessing the 3-ADON genotype were found predominantly aggregated in a high-elevation (cooler) region, while $15-\mathrm{ADON}$, the dominant genotype (>90\%) was found across all sampled locations (6). The species in the FGSC in those regions differs from North America, where $F$. graminearum appears to be the dominant species $(41,43)$; whereas, in the former study, $F$. asiaticum and $F$. graminearum are prevalent and, in the latter, F. graminearum of the 15 -ADON genotype, F. meridionale of the NIV genotype, and $F$. cortaderiae of the NIV and 3-ADON genotypes are the main species.

We did not find evidence that the trichothecene genotype composition differed between wheat and maize kernels in any location. Although DON has been reported as a virulence factor in wheat and maize $(2,16)$, previous studies comparing the type of B-trichothecene as a virulence factor have been contradictory in wheat. In a study with a collection of isolates of different FGSC members, it was suggested that it was the total amount of trichothecenes rather than the specific type of trichothecene (DON or NIV) produced that affected aggressiveness on wheat (14). Moreover, both 3-ADON (13) and 15-ADON (10) isolates have been reported to be very aggressive and causing higher levels of FHB. Conversely, the effect of trichothecene on aggressiveness in maize ears is still unclear. Recently, $16 \mathrm{~F}$. graminearum isolates from wheat and maize in New York, possessing either the 3-ADON or 15-ADON genotype, showed a similar range of aggressiveness and toxigenicity in cross-species pathogenicity tests (19) However, maize-grain surveys in regions where DON and NIV genotypes coexist - that is, in South America (38), Africa (7), Asia (30), and Europe (24) - the NIV genotype is more frequently detected. However, again, pathogenic populations in those regions are composed of multiple species in the FGSC $(4,8,21,38)$. The reasons for such differences in geographical distribution of the trichothecene genotypes around the word are not entirely clear but it has been suggested that environmental conditions and ecological or host preference among the species of the FGSC related to saprophytic or pathogenic fitness might be key factors $(1,4,21,47)$. Because evidence of potential host preference among members of the FGSC was suggested in different parts of the world with relatively high FGSC diversity such as in Korea (21), South Africa (4), and Brazil (6), we can hypothesize that it is the species of the FGSC rather than the trichothecene genotype that plays a major role in ecological habitat adaptation and host preference.

In summary, an intensive sampling of isolates was conducted in four habitats, including maize stubble, maize ears, wheat spikes, and the atmosphere, in three local agroecosystems. As viewed by the composition of trichothecene genotypes, local populations of $F$. graminearum appear not to be structured by these four habitats, inclusive of pathogenic and saprophytic phases of the fungus life cycle. The similar frequency of 3-ADON and 15-ADON in eastern New York (Willsboro), which is less than $400 \mathrm{~km}$ away from the Aurora sampling location in the central area of the state, suggests that regional populations may be differentiated based on selection associated with climatic or landscape features not currently identified. Regional population structure of the pathogen should be examined now from a broader genomic and phenotypic perspective to gain insights into selection pressures shaping these populations and what implications selective forces will have on the epidemiology, pathogenicity, and toxigenicity of this important plant pathogen.

\section{ACKNOWLEDGMENTS}

We thank the Programa de Pós-graduação em Fitotecnia (UFRGS) and Conselho Nacional de desenvolvimento Científico e Tecnológico (CNPq) for providing a graduate scholarship and a sandwich fellowship (Science Without Borders Program) to P. R. Kuhnem and P. Spolti; CNPq for providing a research fellowship to E. M. Del Ponte; Cornell University Hatch Project NYC153473 for providing laboratory and field expenditures for this project; and M. Davis of Cornell University and A. Santangelo of Cornell Cooperative Extension for their generous assistance in collecting samples from the Willsboro and Belmont locations, respectively. Mention of trade names or commercial products in this publication is solely for the purpose of providing specific information and does not imply recommendation or endorsement by the U.S. Department of Agriculture (USDA). USDA is an equal opportunity provider and employer.

\section{LITERATURE CITED}

1. Backhouse, D. 2014. Global distribution of Fusarium graminearum, F. asiaticum and F. boothii from wheat in relation to climate. Eur. J. Plant Pathol. 139:161-173.

2. Bai, G. H., Desjardins, A. E., and Plattner, R. D. 2002. Deoxynivalenolnonproducing Fusarium graminearum causes initial infection, but does not cause disease spread in wheat spikes. Mycopathologia 153:91-98.

3. Bousset, L., and Chèvre, A. M. 2012. Controlling cyclic epidemics on the crops of the agroecosystems: Articulate all the dimensions in the formalisation, but look for a local solution. J. Bot. 2012:1-9.

4. Boutigny, A. L., Ward, T. J., Van Coller, G. J., Flett, B., Lamprecht, S. C., O'Donnell, K., and Viljoen, A. 2011. Analysis of the Fusarium graminearum species complex from wheat, barley and maize in South Africa provides evidence of species-specific differences in host preference. Fungal Genet. Biol. 48:914-920.

5. Campbell, H., Choo, T. M., Vigier, B., and Underhill, L. 2002. Comparison of mycotoxin profiles among cereal samples from eastern Canada. Can. J. Bot. 80:526-532.

6. Del Ponte, E., Spolti, P., Ward, T., Gomes, L. B., Nicolli, C. P., Kuhnem, P. R., da Silva, C. N., and Tessmann, D. J. 2015. Regional and fieldspecific factors affect the composition of Fusarium head blight pathogens in subtropical no-till wheat agroecosystem of Brazil. Phytopathology 105: 246-254.

7. Desjardins, A. E., Busman, M., Manandhar, G., Jarosz, A. M., Manandhar, H. K., and Proctor, R. H. 2008. Gibberella ear rot of maize (Zea mays) in Nepal: Distribution of the mycotoxins nivalenol and deoxynivalenol in naturally and experimentally infected maize. J. Agric. Food Chem. 56: 5428-5436.

8. Desjardins, A. E., and Proctor, R. H. 2011. Genetic diversity and trichothecene chemotypes of the Fusarium graminearum clade isolated from maize in Nepal and identification of a putative new lineage. Fungal Biol. 115:38-48.

9. Dill-Macky, R., and Jones, R. K. 2000. The effect of previous crop residues and tillage on Fusarium head blight of wheat. Plant Dis. 84:71-76.

10. Foroud, N. A., McCormick, S. P., MacMillan, T., Badea, A., Kendra, D. F., Ellis, B. E., and Eudes, F. 2012. Greenhouse studies reveal increased aggressiveness of emergent Canadian Fusarium graminearum chemotypes in wheat. Plant Dis. 96:1271-1279.

11. Gale, L. R., Harrison, S. A., Ward, T. J., O’Donnell, K., Milus, E. A., Gale, S. W., and Kistler, H. C. 2011. Nivalenol-type populations of Fusarium graminearum and $F$. asiaticum are prevalent on wheat in Southern Louisiana. Phytopathology 101:124-134. 
12. Gale, L. R., Ward, T. J., Balmas, V., and Kistler, H. C. 2007. Population subdivision of Fusarium graminearum sensu stricto in the upper Midwestern United States. Phytopathology 97:1434-1439.

13. Gilbert, J., Clear, R. M., Ward, T. J., Gaba, D., Tekauz, A., Turkington, T. K., Woods, S. M., Nowicki, T., and O'Donnell, K. 2010. Relative aggressiveness and production of 3- or 15-acetyl deoxynivalenol and deoxynivalenol by Fusarium graminearum in spring wheat. Can. J. Plant Pathol. 32:146-152.

14. Goswami, R. S., and Kistler, H. C. 2005. Pathogenicity and in planta mycotoxin accumulation among members of the Fusarium graminearum species complex on wheat and rice. Phytopathology 95:1397-1404.

15. Guo, X., Fernando, W., and Seow-Brock, H. 2008. Population structure, chemotype diversity, and potential chemotype shifting of Fusarium graminearum in wheat fields of Manitoba. Plant Dis. 92:756-762.

16. Harris, L., and Desjardins, A. 1999. Possible role of trichothecene mycotoxins in virulence of Fusarium graminearum on maize. Plant Dis. 83:954-960.

17. Ji, L., Cao, K., Hu, T., and Wang, S. 2007. Determination of deoxynivalenol and nivalenol chemotypes of Fusarium graminearum isolates from china by PCR assay. J. Phytopathol. 155:505-512.

18. Keller, M., Thomason, W., and Schmale, D. G. 2011. The spread of a released clone of Gibberella zeae from different amounts of infested corn residue. Plant Dis. 95:1458-1464.

19. Kuhnem, P. R. Del Ponte, E., Dong, Y., and Bergstrom, G. C. Fusarium graminearum isolates from wheat and maize in New York show similar range of aggressiveness and toxigenicity in cross-species pathogenicity tests. Phytopathology. In press.

20. Landschoot, S., Audenaert, K., Waegeman, W., Pycke, B., Bekaert, B., De Baets, B., and Haesaert, G. 2011. Connection between primary Fusarium inoculum on gramineous weeds, crop residues and soil samples and the final population on wheat ears in Flanders, Belgium. Crop Prot. 30:1297-1305.

21. Lee, S. H., Lee, J., Nam, Y. J., Lee, S., Ryu, J. G., and Lee, T. 2010. Population structure of Fusarium graminearum from maize and rice in 2009 in Korea. Plant Pathol. J. 26:321-327.

22. Leslie, J. F., and Summerell, B. A. 2006. The Fusarium Laboratory Manual. Wiley Online Library, Ames, IA.

23. Liang, J. M., Xayamongkhon, H., Broz, K., Dong, Y., McCormick, S. P., Abramova, S., Ward, T. J., Ma, Z. H., and Kistler, H. C. 2014. Temporal dynamics and population genetic structure of Fusarium graminearum in the upper Midwestern United States. Fungal Genet. Biol. 73:83-92.

24. Logrieco, A., Mulè, G., Moretti, A., and Bottalico, A. 2002. Toxigenic Fusarium species and mycotoxins associated with maize ear rot in Europe. Eur. J. Plant Pathol. 108:597-609.

25. Margosian, M. L., Garrett, K. A., Hutchinson, J. M. S., and With, K. A. 2009. Connectivity of the American agricultural landscape: Assessing the national risk of crop pest and disease spread. Bioscience 59:141-151.

26. McMullen, M., Bergstrom, G., De Wolf, E., Dill-Macky, R., Hershman, D., Shaner, G., and Van Sanford, D. 2012. A unified effort to fight an enemy of wheat and barley: Fusarium head blight. Plant Dis. 96:1712-1728.

27. Miller, J. D., Greenhalgh, R., Wang, Y., and Lu, M. 1991. Trichothecene chemotypes of three Fusarium species. Mycologia 83:121-130.

28. Munkvold, G. P. 2003. Epidemiology of Fusarium diseases and their mycotoxins in maize ears. Eur. J. Plant Pathol. 109:705-713.

29. Munkvold, G. P., and O'Mara, J. K. 2002. Laboratory and Growth chamber evaluation of fungicidal seed treatments for maize seedling blight caused by Fusarium species. Plant Dis. 86:143-150.

30. Ndoye, M., Zhang, J. B., Wang, J. H., Gong, A. D., Li, H. P., Qu, B., Li, S. J., and Liao, Y. C. 2012. Nivalenol and 15-acetyldeoxynivalenol chemotypes of Fusarium graminearum clade species are prevalent on maize throughout China. J. Phytopathol. 160:519-524.

31. Pereyra, S. A., and Dill-Macky, R. 2008. Colonization of the residues of diverse plant species by Gibberella zeae and their contribution to Fusarium head blight inoculum. Plant Dis. 92:800-807.
32. Pereyra, S. A., Dill-Macky, R., and Sims, A. L. 2004. Survival and inoculum production of Gibberella zeae in wheat residue. Plant Dis. 88: 724-730.

33. Puri, K. D., and Zhong, S. 2010. The 3ADON population of Fusarium graminearum found in North Dakota is more aggressive and produces a higher level of DON than the prevalent 15ADON population in spring wheat. Phytopathology 100:1007-1014.

34. Quarta, A., Mita, G., Haidukowski, M., Logrieco, A., Mulè, G., and Visconti, A. 2006. Multiplex PCR assay for the identification of nivalenol, 3- and 15-acetyl-deoxynivalenol chemotypes in Fusarium. FEMS Microbiol. Lett. 259:7-13.

35. Reid, L., Mather, D., and Hamilton, R. 1996. Distribution of deoxynivalenol in Fusarium graminearum-infected maize ears. Phytopathology 86:110-114.

36. Reid, L., Nicol, R. W., Ouellet, T., Savard, M., Miller, J. D., Young, J. C., Stewart, D. W., and Schaafsma, A. W. 1999. Interaction of Fusarium graminearum and $F$. moniliforme in maize ears: Disease progress, fungal biomass, and mycotoxin accumulation. Phytopathology 89:1028-1037.

37. Reynoso, M. M., Ramirez, M. L., Torres, A. M., and Chulze, S. N. 2011. Trichothecene genotypes and chemotypes in Fusarium graminearum strains isolated from wheat in Argentina. Int. J. Food Microbiol. 145: 444-448.

38. Sampietro, D. A., Díaz, C. G., Gonzalez, V., Vattuone, M. A., Ploper, L. D., Catalan, C. A. N., and Ward, T. J. 2011. Species diversity and toxigenic potential of Fusarium graminearum complex isolates from maize fields in northwest Argentina. Int. J. Food Microbiol. 145: 359-364.

39. Sarver, B. A. J., Ward, T. J., Gale, L. R., Broz, K., Kistler, H. C., Aoki, T., Nicholson, P., Carter, J., and O'Donnell, K. 2011. Novel Fusarium head blight pathogens from Nepal and Louisiana revealed by multilocus genealogical concordance. Fungal Genet. Biol. 48:1096-1107.

40. Schmale, D. G., III, Leslie, J. F., Zeller, K. A., Saleh, A. A., Shields, E. J., and Bergstrom, G. C. 2006. Genetic structure of atmospheric populations of Gibberella zeae. Phytopathology 96:1021-1026.

41. Schmale, D. G., Wood-Jones, A. K., Cowger, C., Bergstrom, G. C., and Arellano, C. 2011. Trichothecene genotypes of Gibberella zeae from winter wheat fields in the eastern USA. Plant Pathol. 60:909-917.

42. Spolti, P., Del Ponte, E. M., Cummings, J. A., Dong, Y., and Bergstrom, G. C. 2014. Fitness attributes of Fusarium graminearum isolates from wheat in New York possessing a 3-ADON or 15-ADON trichothecene genotype. Phytopathology 104:513-519.

43. Starkey, D. E., Ward, T. J., Aoki, T., Gale, L. R., Kistler, H. C., Geiser, D. M., Suga, H., Tóth, B., Varga, J., and O‘Donnell, K. 2007. Global molecular surveillance reveals novel Fusarium head blight species and trichothecene toxin diversity. Fungal Genet. Biol. 44:1191-1204.

44. Sutton, J. C. 1982. Epidemiology of wheat head blight and maize ear rot caused by Fusarium graminearum. Can. J. Plant Pathol. 4:195-209.

45. Von der Ohe, C., Gauthier, V., Tamburic-Illincic, L., Brule-Babel, A., Fernando, W. G. D., Clear, R., Ward, T. J., and Mideaner, T. 2010. A comparison of aggressiveness and deoxynivalenol production between Canadian Fusarium graminearum isolates with 3-acetyl and 15- acetyldeoxynivalenol chemotyples in field-grown spring wheat. Eur. J. Plant Pathol. 127:407-417.

46. Ward, T. J., Bielawski, J. P., Kistler, H. C., Sullivan, E., and O’Donnell, K. 2002. Ancestral polymorphism and adaptive evolution in the trichothecene mycotoxin gene cluster of phytopathogenic Fusarium. Proc. Natl. Acad. Sci. USA 99:9278-9283.

47. Ward, T. J., Clear, R. M., Rooney, A. P., O’Donnell, K., Gaba, D., Patrick, S., Starkey, D. E., Gilbert, J., Geiser, D. M., and Nowicki, T. W. 2008. An adaptive evolutionary shift in Fusarium head blight pathogen populations is driving the rapid spread of more toxigenic Fusarium graminearum in North America. Fungal Genet. Biol. 45:473-484. 